\title{
TITLE: MULTIDISCIPLINARY IMAGING OF ROCK PROPERTIES IN CARBONATE RESERVOIRS FOR FLOW-UNIT TARGETING
}

\author{
SEMI-ANNUAL TECHNICAL REPORT
}

Reporting Period: 5/15/03 - 11/15/04

Author: Stephen C. Ruppel

March 2004

Contract No. DE-FC26-01BC15351

Contractor Name and Address:

Bureau of Economic Geology, John A. and Katherine G. Jackson School of Geosciences, The University of Texas at Austin, Austin, TX 78713 


\section{DISCLAIMER}

“This report was prepared as an account of work sponsored by an agency of the United States Government. Neither the United States Government nor any agency thereof, nor any of their employees, makes any warranty, express or implied, or assumes any legal liability or responsibility for the accuracy, completeness, or usefulness of any information, apparatus, product, or process disclosed, or represents that its use would not infringe privately owned rights. Reference herein to any specific commercial product, process, or service by trade name, trademark, manufacturer, or otherwise does not necessarily constitute or imply its endorsement, recommendation, or favoring by the United States Government or any agency thereof. The views and opinions of authors expressed herein do not necessarily state or reflect those of the United States Government or any agency thereof.” 


\begin{abstract}
Progress on the study of the Fullerton Clear Fork reservoir ( Figure 1) continues at an excellent pace. Major accomplishments during the past 6 months include: (1) revision and update of the reservoir model used for simulation in the Phase 1 model area, (2) completion of cycle correlations in the Phase 1 and 2 areas and all intervening areas of the field, (3) continued refinement of the velocity-based inversion model from the 3-D seismic volume for porosity characterization, (4) continued quality control analysis of wireline logs. Detailed analyses of infill drilling potential were prepared and delivered to the field operator, ExxonMobil, and form the basis for a drilling program to be implemented in 2004. Preliminary results of the study were presented at a technology transfer workshop in May and at the annual meeting of the West Texas Geological Survey in October. Wee have made these reports available through the Bureau's website. A summary of project results is also presented at the Bureau website.
\end{abstract}




\section{Table of Contents}

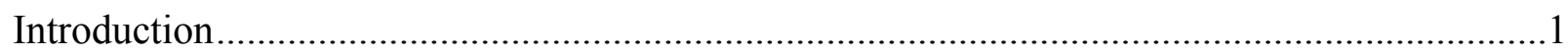

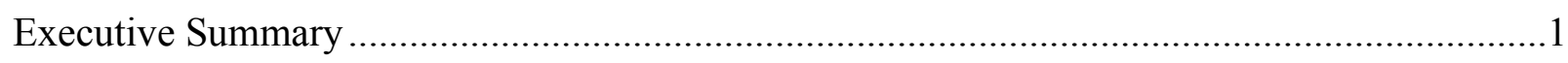

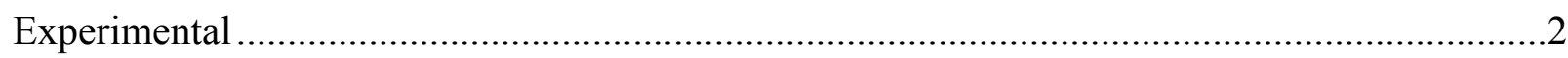

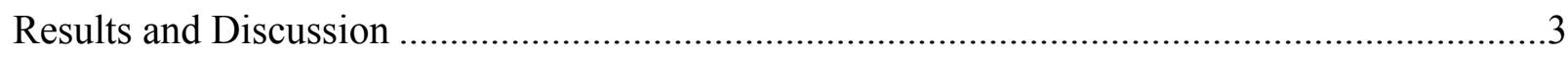

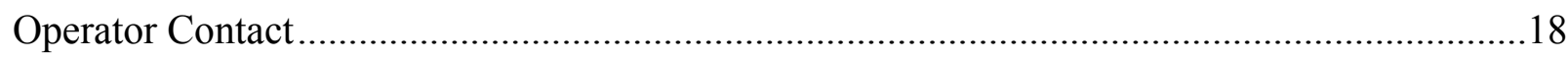

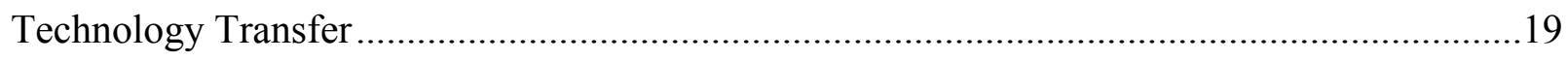

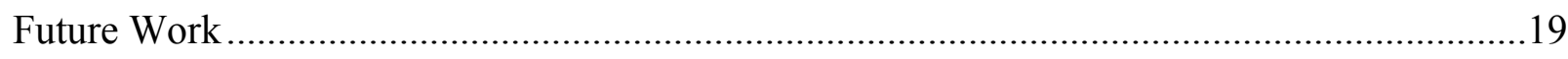

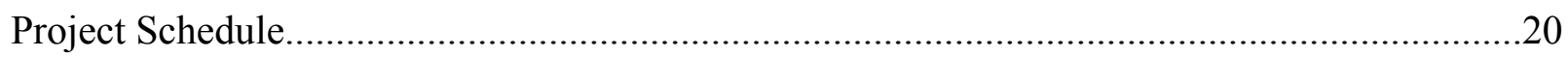

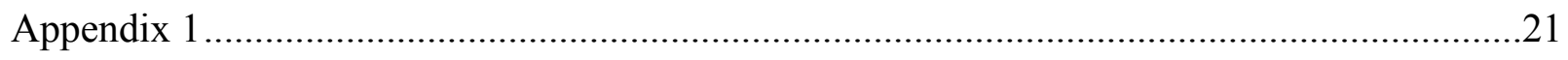

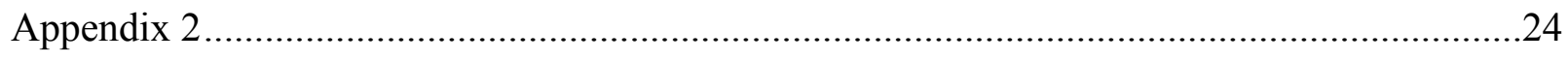




\section{Introduction}

We have made excellent progress toward most goals and objectives of the project, which remain essentially unchanged from the original proposal. This report describes the work accomplished on the project during months 13 through 18 of the project.

\section{LEONARDIAN OUTCROPS AND RESERVOIRS}

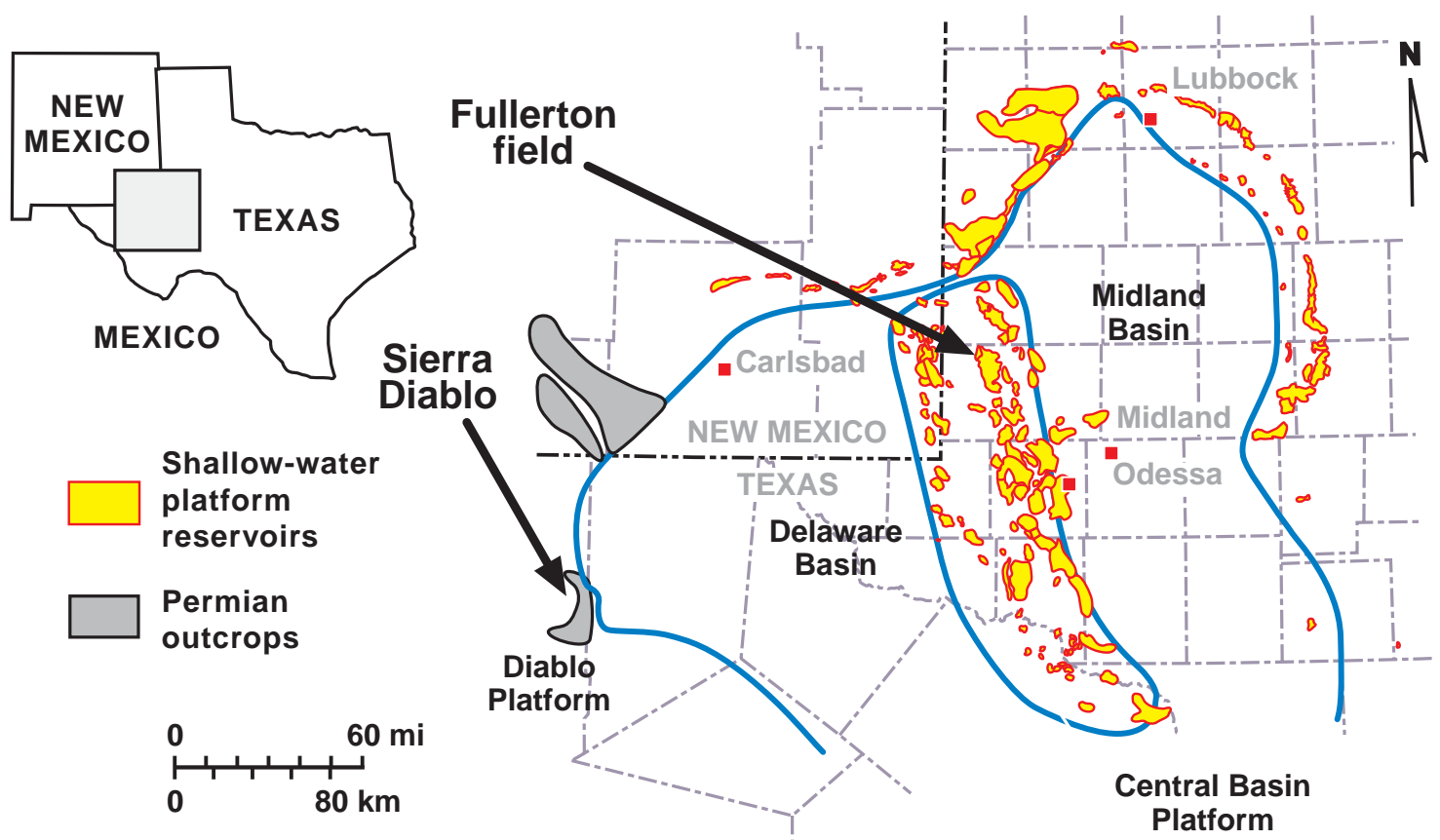

Figure 1. Regional map of the Permian Basin showing location of reservoir study and analogous outcrops.

\section{Executive Summary}

Progress has been made on several fronts during the last 6 months. Major focus continues to be in the areas of (1) fieldwide core- and facies- based stratigraphic studies, (2) interpretation of special core analysis data for in terms of its impact on saturation and 
permeability modeling, (3) refinement of the inversion model to relate seismic velocity data to reservoir porosity, (4) quality analysis of wireline log data, and (4) refinement of simulation runs for the Phase 1 area reservoir model. Two analyses of infill drilling potential were also completed and were used by the operator to design a drilling program to be implemented in 2004. The one remaining element of the study that has yet to be started involves the creation of a virtual reality model of the reservoir. This activity will be started in the next 6 month period.

\section{Experimental}

The special core analysis of 30 newly sampled core plugs has been completed. Fifteen of these samples were analyzed for formation factor, resistivity index, air-oil capillary pressure, and high pressure mercury injection capillary pressure. The remaining 15 were tested for high pressure mercury injection capillary pressure only. These data are now being used to update and modify previously reported saturation and rock fabric relationships.

We have decided to collect 210 new plug samples from the FCU 7630 core to expand our data base on rock fabric distribution and properties in the reservoir. In order to carry out these rock fabric studies, we will have porosity and permeability measured on the plugs and then have thin sections prepared from each plug for characterization of pore types and rock fabric. 


\section{Results and Discussion}

As described in previous reports study of the Fullerton Clear Fork reservoir has been subdivided into three phases. The first two phases, Phase 1 and Phase 2 (Figure 2), focus on two small areas of the reservoir; Phase 3 involves study of the remaining parts of the reservoir and an integration of all three areas. During the last 6 months of the project, we have made substantial progress on all three phases of the project and on most project tasks including Task 1, Construct Cycle Stratigraphic Framework, Task 2, Characterize and Model Rock Fabrics, and Task 4, Correlate and Model Rock Properties and 3-D Seismic Attributes.

All Task 1 activities have been completed in the Phase 1 and 2 areas and are nearing completion in the remainder of the field. Task 2 activities are complete for the

phase 1 area and nearly complete for the phase two area. Task 4 activities are focused on the Phase 2 area are continuing. 


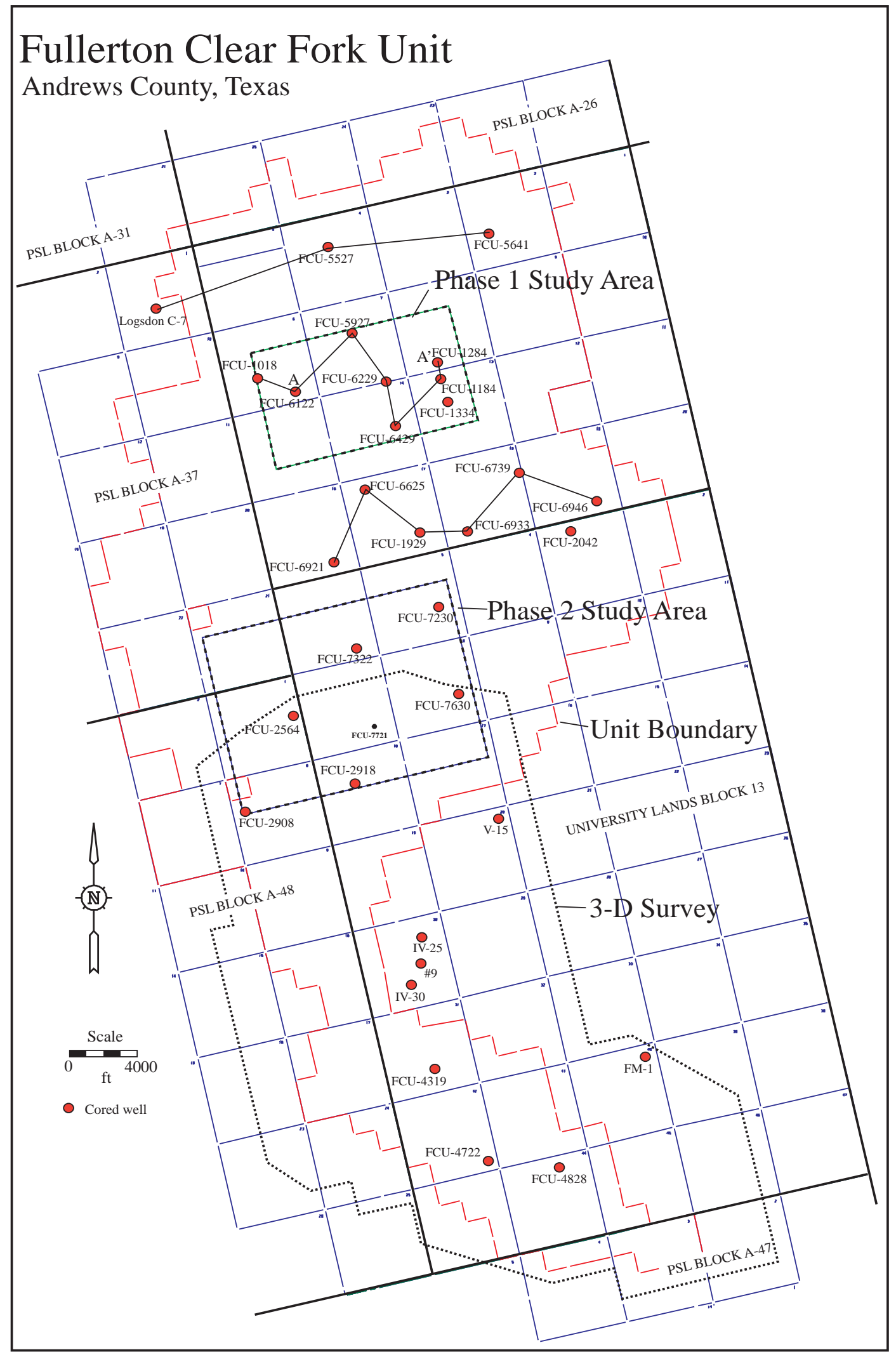

Figure 2. Map of field showing location of study areas, cores, and 3-D seismic data. 
Subtask 1.1 Describe Facies and Cyclicity in Cores.

More than 11,000 feet of core and more than 1300 thin sections have now been described. This includes all cores in the most data- and oil-rich part of the field (the Phase 1 and 2 study areas) and the intervening areas in the northern part of the field (see Figure 2). Cores remaining to be described include those in the extreme northern and southern parts of the field (Figure 2). These studies show that the sequence stratigraphic model (Figure 3) developed early on in the study is applicable over the entire field.

\section{SEQUENCE STRATIGRAPHIC MODEL Lower Clear Fork - Wichita - Abo: Fullerton Field}

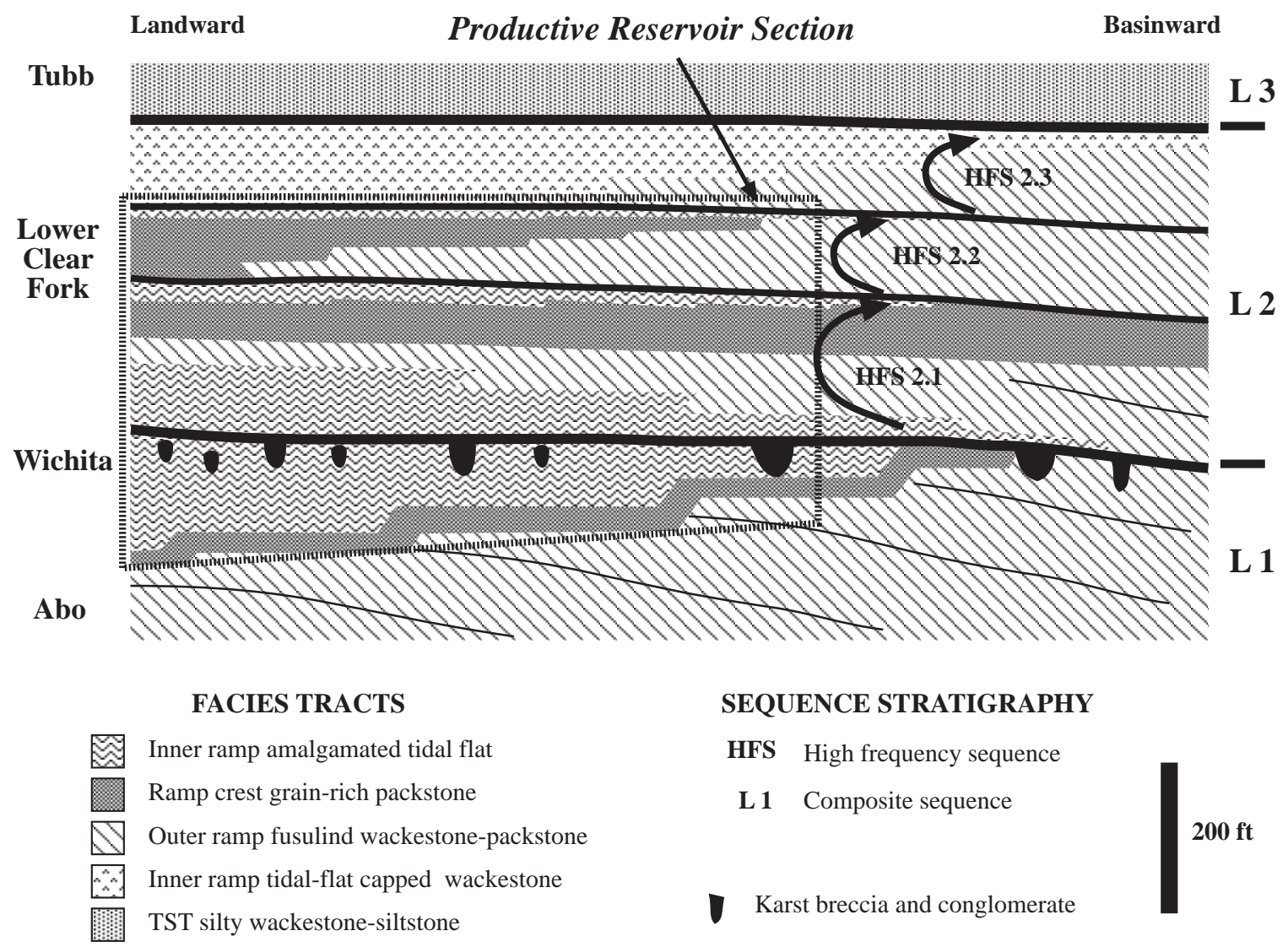

Figure 3. Sequence stratigraphic model of the Clear Fork reservoir at Fullerton field. 


\section{Subtask 1.2 Describe Facies and Cyclicity in Outcrops.}

We have completed most of outcrop characterization work and have used the results to help constrain the depositional model used to construct the reservoir model. No additional work was done during the past 6 months.

\section{Subtask 1.3 Develop Wireline Correlation Framework.}

A detailed wireline correlation framework has been established (using integrated core and log data) and correlated in wells with CNL or SNP porosity log throughout the main body of the field, including the Phase 1 Study Area, the Phase 2 Study Area, and the area between the two. Correlations remain to be done in the northernmost and southern parts of the field. Our correlations consist of 27 interpreted cycle tops in Leonardian composite sequence L2 (lower Clear Fork) and 10 porosity-based horizons as well as 2 distinct flooding events in Leonardian composite sequence L1 (Wichita). To date more than 28,ooo stratigraphic picks have been made. In the Phase 1 Study Area, cycle tops and horizons in the reservoir interval were divided into a typically high-porosity top and low-porosity base to create 48 layers for flow simulation.

Our correlation strategy is primarily based on facies and porosity patterns of cycles observed in core and our interpretation that most of the reservoir was deposited in a platform setting with little internal topography. Core observations have shown that cycles tend to contain a high-porosity top and a low porosity base, confirmed by both core analysis and wireline porosity logs. Subtidal cycles shallow upward from lowporosity mud-dominated facies into high-porosity grain-dominated facies. Similarly, we observe low-accommodation cycles consisting of basal mudstones with very little 
porosity capped by tidal flat facies containing higher, commonly fenestral, porosity. We also observe cycles consisting of subtidal wackestones capped by tidal flat facies that are not always more porous than the wackestone bases. In these cases, gamma ray curves, particularly spectral gamma ray curves, are useful to identify the typically high-GR tidal flat cap.

$\underline{\text { Subtask 2.1 Measure Petrophysical Properties in Core. }}$

All of the original 30 samples sent off for analysis have been completed. Fifteen of the samples had formation factor, resistivity index, air-oil capillary pressure, and high pressure mercury injection capillary pressure tests performed on them. The remainder had high pressure mercury injection capillary pressure tests only performed. Initial results indicate that the moldic rocks respond petrophysically very much like grain dominated rocks. This result is significantly different than expected. Further review of the thin sections lead to observations suggesting that the pore structure is significantly more complicated than a traditionally modeled moldic pore system. To test this, 3 additional samples have been sent off for the full suite of tests described above. These samples appear to have pore structure.

As described above, we will collect 210 additional plug samples from the FCU 7630 core to expand our data base on rock fabric distribution and properties in the reservoir. 


\section{$\underline{\text { Subtask 2.2 Define and Characterize Rock Fabrics }}$}

All remaining available thin sections from the area of the field located between the two study areas ( Figure 2) were described to characterize rock fabrics and assign petrophysical classes. Nearly 300 thin sections were described from wells FCU 6625, 6739, 6921, 6933, and 6946 (Figure 2), which brings the total number of thin sections described thus far in the project to a total of more than 1300 . We also used existing core analysis data from these wells to calculate apparent rock fabric numbers. We have combined this work with our previous observations from other parts of the field to map changes in petrophysical class over the Phase 1 Study Area, Phase 2 Study Area, and the area between the two ( Figure 2), which includes the area of highest initial production.

Map patterns of changes in petrophysical classes by sequence are as follows:

- The Wichita, or the peritidal portion of Leonardian composite sequence 1 (L1), contains dominantly petrophysical class 3 fabrics, with a few thin and generally non-correlative class 2 intervals.

- Lower Clear Fork Leonardian high-frequency sequence 2.1 (L2.1), consists of class 2 dolostones and limestones overlain by class 3 dolostones in the Phase 1 Study Area. While class 3 dolostones characterize the latest cycles in this high-frequency sequence throughout the main body of the field, the underlying section changes to include an interval of class 1 dolostones in addition to class 2 dolostones (Figure 4 ) in 
the central area of the field and parts of the Phase 2 Study Area. In the eastern and southern portions of the Phase 2 Study Area, this section becomes dominantly class 1 dolostone interbedded with class 2 and class 3 limestones. The complex nature of these alternating fabrics in this area has prompted us to resample the FCU 7630 core for plugs with matching thin sections.

- Lower Clear Fork Leonardian high-frequency sequence 2.2 (L2.2) contains petrophysical class 1 dolostones throughout the main body of the field, with the exception of an area of class 2 limestone in the northwestern part of the Phase 1 Study Area.

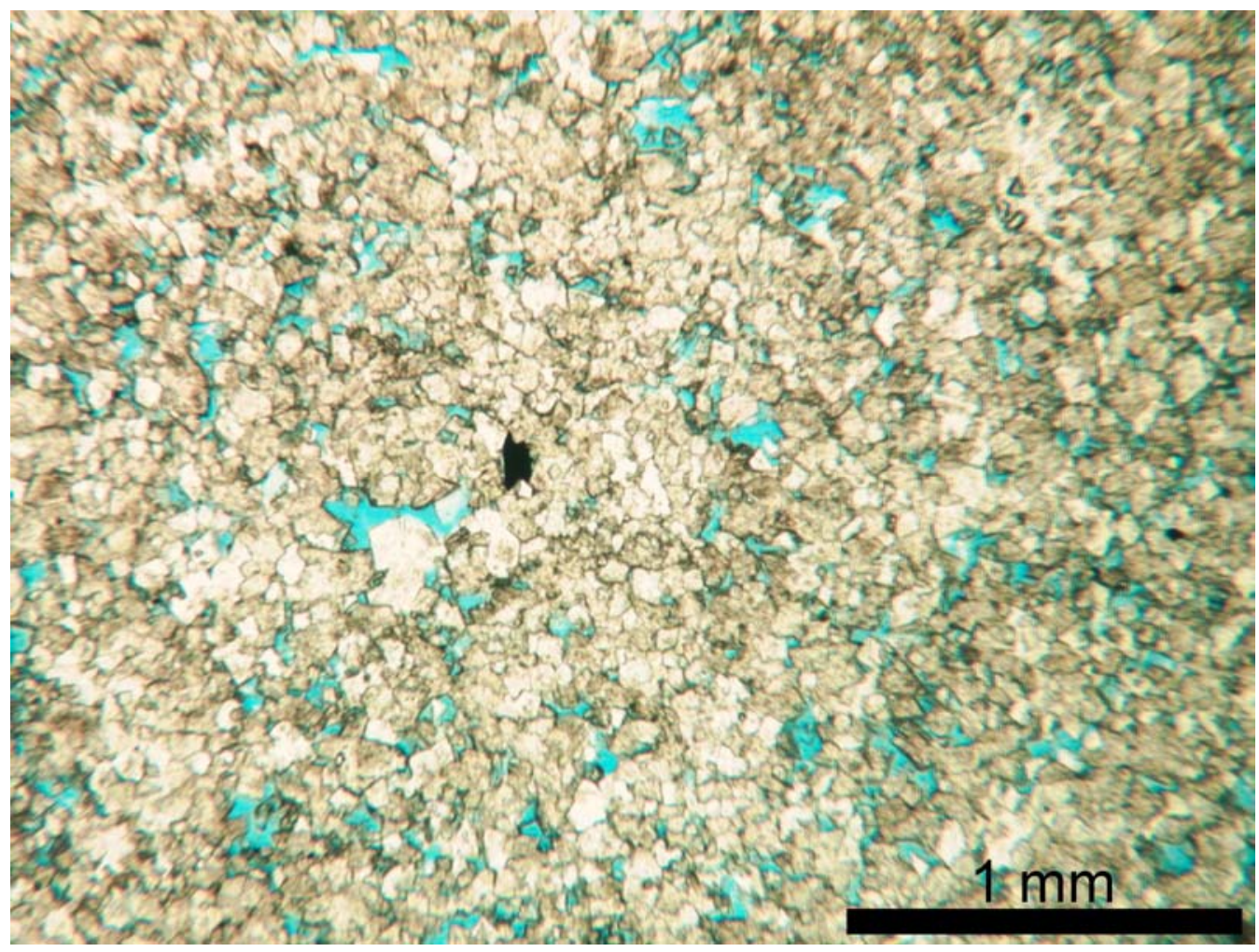

Figure 4. Petrophysical class 2 dolostone from L2.1, FCU 6933 
- Lower Clear Fork Leonardian high-frequency sequence 2.3 (L2.3) contains primarily very low porosity class 3 fabrics in most areas and is therefore considered non-reservoir. However, in the southeastern portion of the Phase 2 Study Area, apparent rock fabric numbers calculated from the FCU 7630 core analysis suggest petrophysical class 1 and class 2 fabrics. Thus, we have also resampled this core to assess the possibility of reservoir-quality rocks in L2.3 in this area.

\section{Subtask 2.3 Collect relative-permeability and capillary-pressure data.}

Past work with capillary pressure measurements in moldic rocks indicate that the measured capillary pressure curves are inordinately pessimistic. Core samples identified as having moldic pores have had two types of capillary pressure measurements made on them. Both air-oil high speed centrifuge capillary pressure and high pressure mercury injection capillary pressure measurements have been made. By varying the wettability of the injection fluid we hope to test the hypothesis that the measurement design may have limitations in moldic pore systems.

\section{Subtask 2.4 Calibrate Wireline Logs for Rock Fabric Identification.}

We have made good progress on this task in two areas. First we are continuing our efforts understand the relationships between resistivity response and rock fabric. As first order effects, the resistivity log responds not only to the porosity and saturation make-up of the rock, but the distribution and type of that porosity in that rock. Methods to compensate for saturation make-up 
are being derived while simultaneously preserving the porosity distribution effects on the logs. The other need is to compensate for the total porosity response of the rock. In order to do this a consistent or normalized porosity response needs to be considered.

This has led to the need to develop global normalization methods that are internally consistent when normalizing various porosity log types. Fullerton field has a development history that spans several decades. During this time large advances in wireline measurement technology have been made. Methods to normalize this data when not only are tool responses changing, but the baseline response for normalization is also changing spatially, are being worked out.

By both removing saturation effects from the resistivity logs and providing a reduction in the error or "noise" in the total porosity data through an advanced normalization methodology, we will acquire an improved understanding of log variation associated specifically with variations in rock-fabric.

Subtask 3.1. Collect rock-mechanics data (subcritical crack indices).

This task has been deferred until rock fabrics are more accurately understood.

Subtask 3.2. Model fracture growth

No significant fractures have been observed to date. This task has been deferred.

Subtask 4.1 Construct 3-D Seismic Attribute Model of Reservoir Porosity.

We continued to work on seismic attribute analysis and inversion of the 3-D seismic data. The purpose is to integrate high-resolution stratigraphic information from 
well-log interpretation to seismic inversion for improved 3-D mapping of carbonate reservoirs. Following a successful testing of progressive inversion on Fullerton field 3D seismic data, we used Apache Canyon lower Clear Fork and Abo outcrop analog data to try to understand how geologic modeling can control seismic inversion and how to build high quality, high resolution geologic models for inversion.

Numerous studies have suggested that without high-frequency a priori information, seismic inversion can be correctly performed only in the effective frequency range of a given seismic data set (commonly $5-70 \mathrm{~Hz}$ ). Beyond the signal range, inversion is deemed to be unreliable and erroneous. Any lower $(0-5 \mathrm{~Hz})$ and higher (70$400 \mathrm{~Hz}$ ) frequency, stratigraphic details beyond seismic frequency spectrum must come from other sources, primarily well data. With a proper inversion algorithm, the highresolution a priori information from well data mapping can pass through to inversion. Our recent research shows that the resolution of the a priori model controls the resolution of inversion. For example, a model-based inversion of 30-Hz Ricker synthetic profile produced an ultra-high resolution AI estimation (Figure 5, inversion) when the measured outcrop AI model itself was used as a priori model (Figure 5, model); the result deteriorates if the a priori model was replaced by a smoothed outcrop AI section. As a result, the resolution of the inversion is similar to that of the a priori model (compare model and inversion in Figure 5). Apparently, a high-resolution a priori model from well and outcrop data is key for a geologically meaningful high-resolution inversion.

Our work on the outcrop model also showed that the accuracy of geologic framework is key for the quality of the initial model. Geologic knowledge provides vital information on how a high-resolution a priori model should be build. Stratigraphic and 
facies architecture dictates the stacking pattern of reservoir and flow units, which will transfer to estimated AI model from inversion. An incorrect correlation of well logs can result in disastrous outcome. However, there is no guarantee that an accurate stratigraphic framework can be converted into accurate two-way time structural (thickness) model used in inversion. Limited availability of well data forces us to use low-frequency seismic data when mapping high-frequency geology between and beyond wells. The work on the outcrop suggests that progressive inversion scheme is helpful in solving this problem.
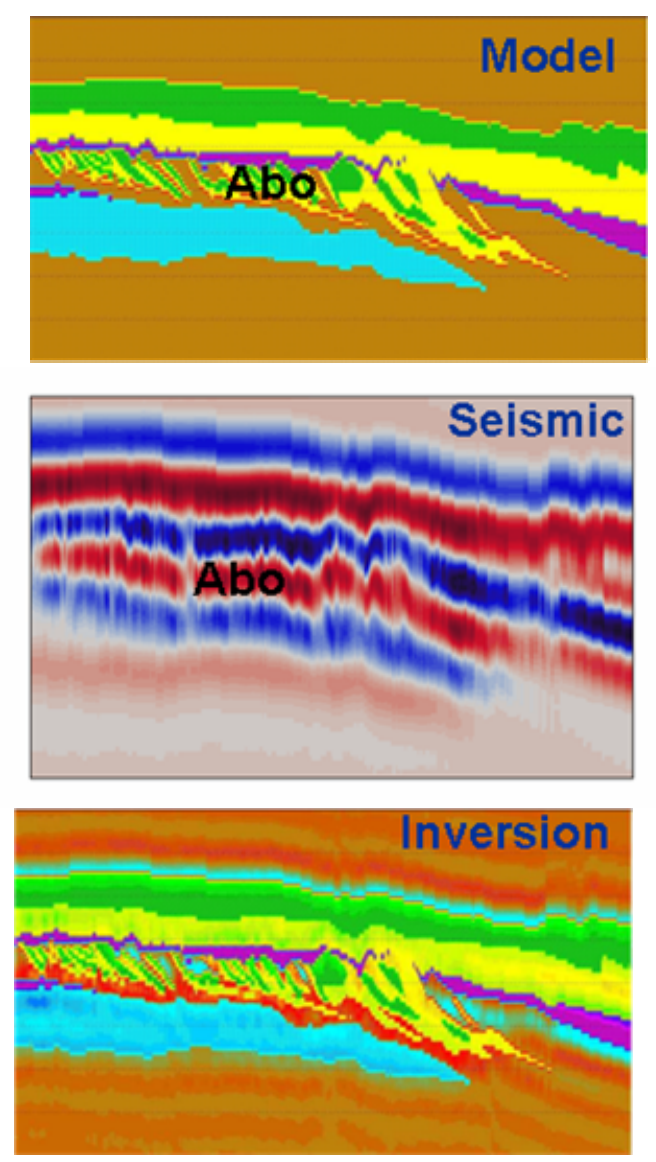

Figure 5. Apache Canyon Abo outcrop AI model (10 ft resolution, upper), synthetic seismic section made with $40 \mathrm{~Hz}, 90$-degree Ricker wavelet (middle), and result of model-based inversion using the outcrop model itself (upper) as a priori model input (lower). 
Subtask 4.2. Integrate 3-D data with rock-fabric and cycle-stratigraphic data.

Based on preliminary results of progressive inversion in Phase II area, Fullerton

field, we tested a procedure to convert a seismically derived AI volume into a porosity volume, and then into a permeability volume (Figure 6). The conversion from AI to porosity for lower Clear Fork and Wichita reservoirs was completed by applying a linear transform formulated from well log analysis between AI logs and porosity logs (described in last report). The conversion from the porosity to permeability was attempted by first assigning rock-fabric numbers for different reservoir intervals, and then calculating permeability values based on rock-fabric-dependent transforms. For this test, Wichita reservoir was assigned a rock-fabric number of 3, and the lower Clear Fork (HFS 2.1 and 2.2) reservoirs a rock-fabric number of 2. In the future study, we will fine-tune the assignment and better results are expected. We hope that by applying similar approach we can improve permeability distribution of the final reservoir and simulation models. 
Al Inversion

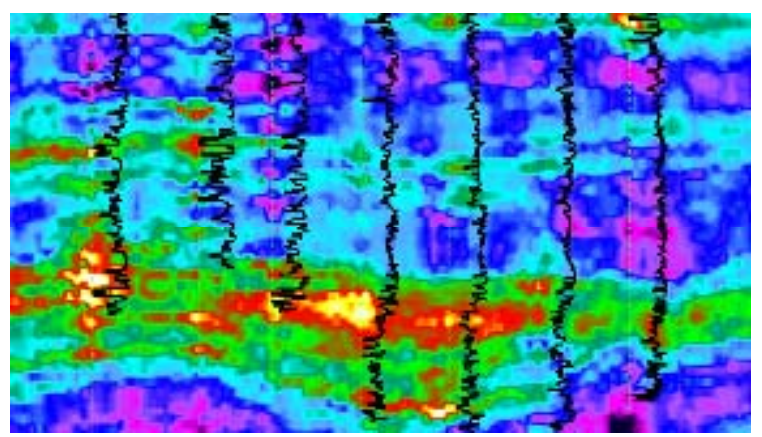

Porosity (\%)
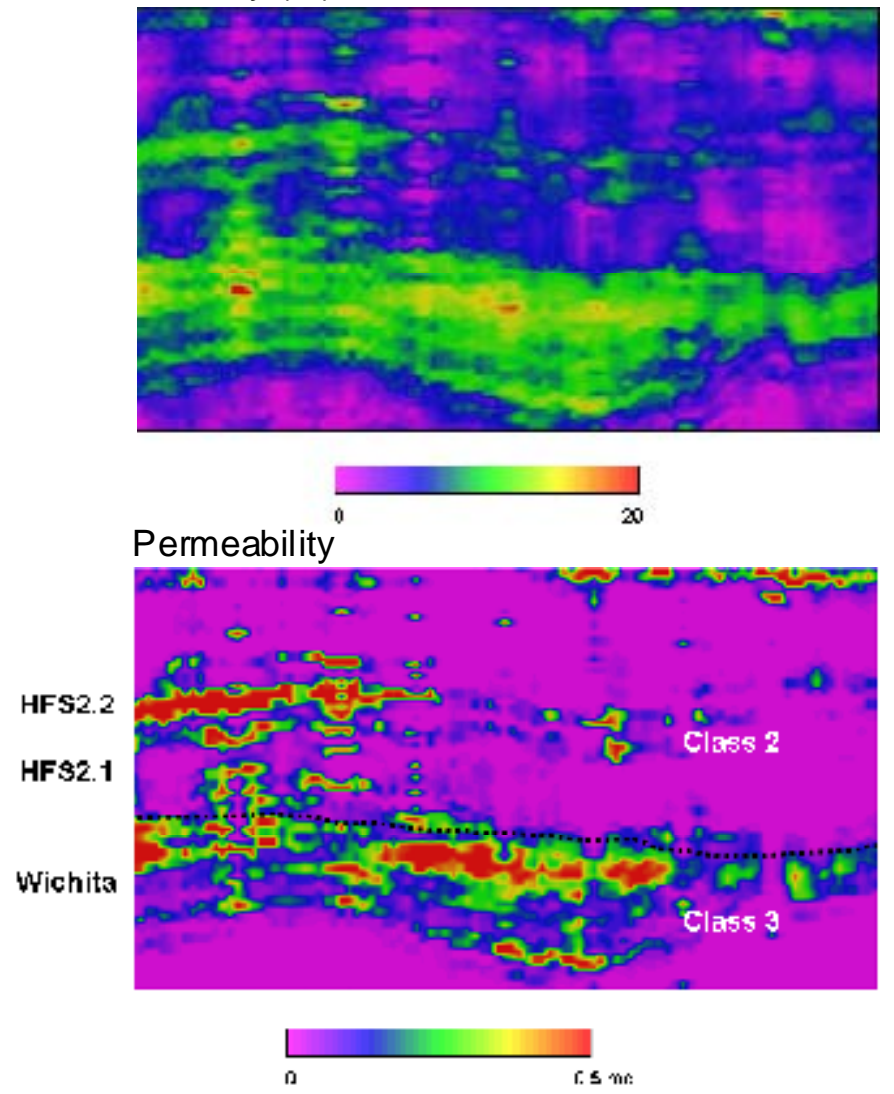

Figure 6. Porosity and permeability calculated from seismic inversion

Subtask 4.3. Distribute reservoir properties through interwell space.

There are two parts to this task. The first involves constructing a geologically realistic reservoir model for the Phase 1 area, a 2,000̃ac study area was selected for 
reservoir simulation study (Figure 2), and the second involves extending this model to the entire field. The first part has been done; the second is still underway.

The purpose of the phase 1 area model is to provide an accurate reservoir model to simulate flow through using historical reservoir and production data and to identify improved recovery methods for maximizing oil recovery. To do this we created a model containing 39 rock-fabric flow layers based on high-frequency depositional cycles defined in cores and correlated using wireline logs. The flow layers form the basic architectural elements for distributing rock properties throughout the model. A fine-scale geological model containing 3.2 million cells (140x90x256) was then constructed first using RMS from ROXAR Inc., and porosity, permeability and water saturation were mapped through the 3-D space. The geological model was then scaled up to a coarse reservoir model containing 130,000 cells $(73 \times 48 \times 39)$ for reservoir simulation.

The simulation study was divided into three phases sensitivity study, history matching, and performance prediction. From the sensitivity study we ranked the importance of reservoir parameters affecting production performance. Then using history matching, we defined optimal fluid and rock properties (the resultant porosity model from this work in shown in figure 7). We have already used the results of simulation to begin to define bases for performance prediction and to help define possible sites for recompletion and infill drilling in the Phase 1 area. These observations have been delivered to ExxonMobil in the form of recommendations for drilling. Although a successful simulation has been completed, we are continuing to investigate the importance and impact of interwell attribute modeling on simulation performance and to update model attributes based on newly gathered data such as recently received special 
core analysis data bearing or permeability and oil saturation relationships. This work will bear on fundamental questions of how reservoir models in carbonate rocks should best be constructed.

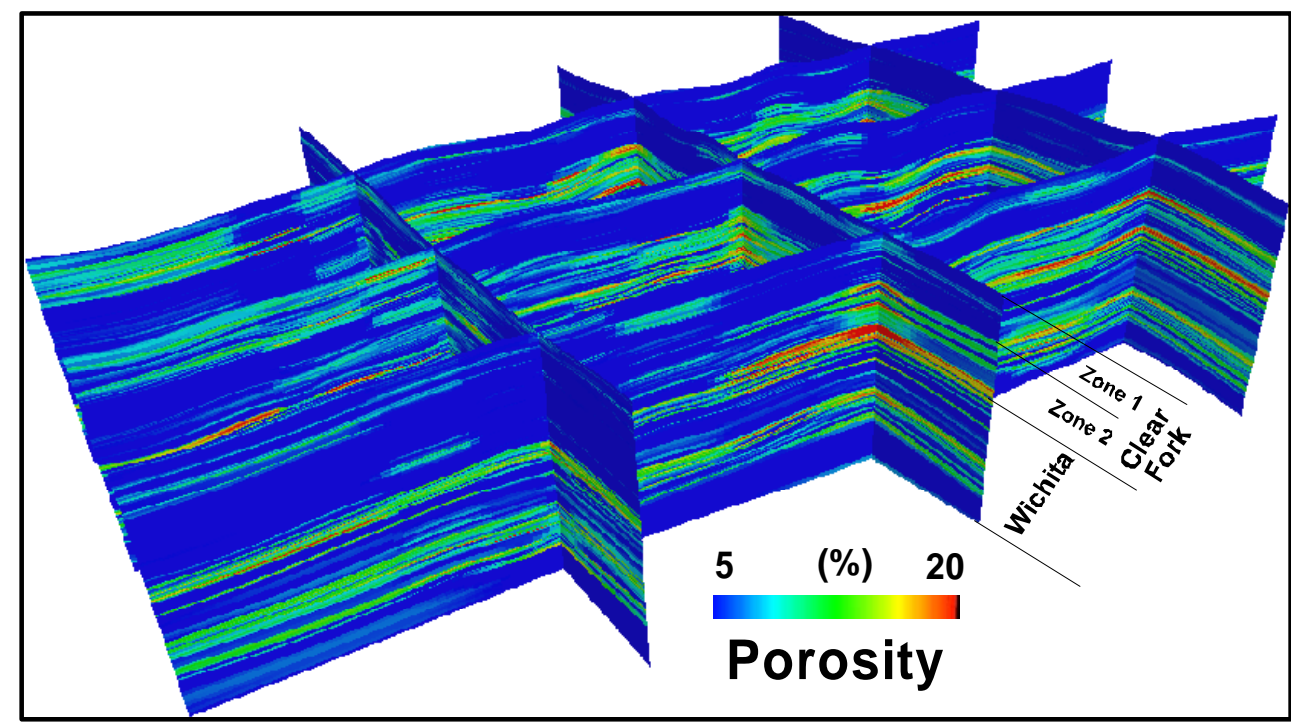

Figure 7. Porosity distribution in the study area, Fullerton Clear Fork Unit.

A preliminary model, of the entire field is shown in figure 8 . we have already recalculated porosity for all reliable porosity log suites in the field and are using these data along with new, cycle-based correlations to develop a field-wide reservoir model. 


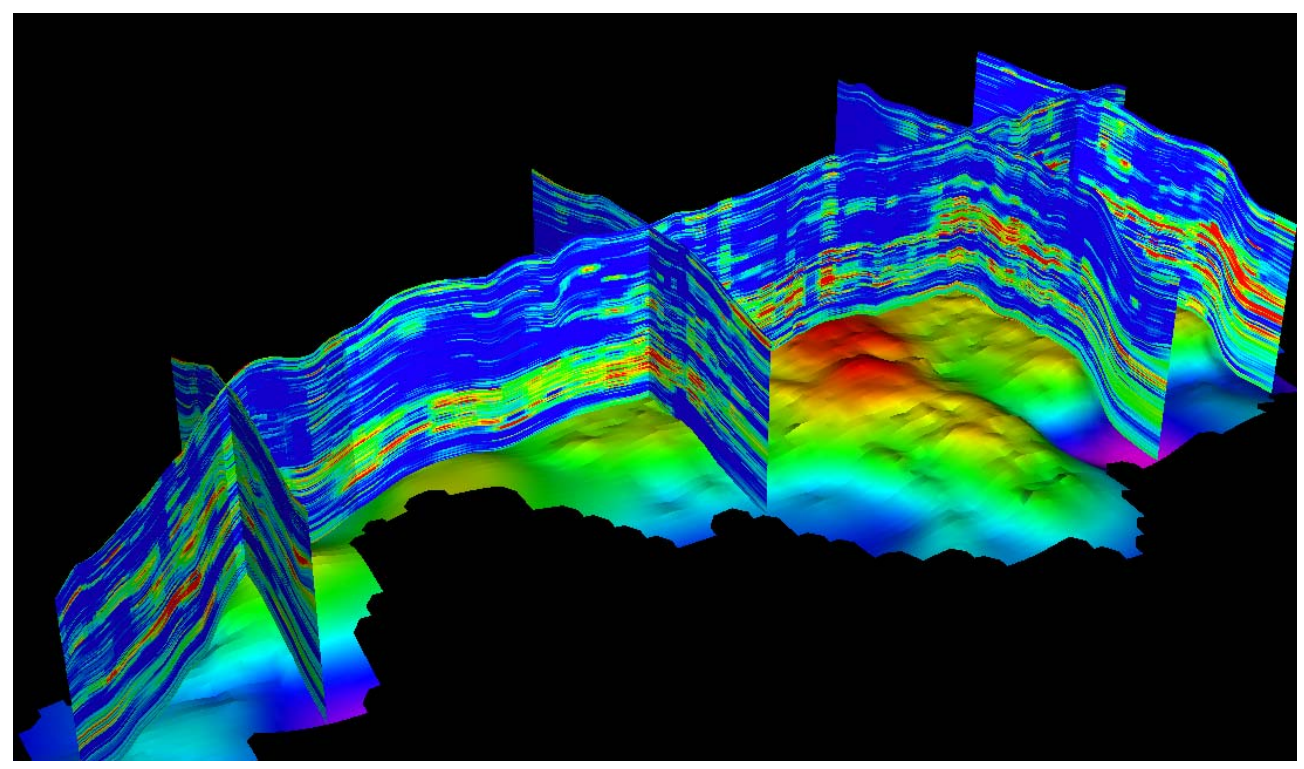

Figure 8. Preliminary model of porosity distribution in Fullerton Clear Fork Unit.

\section{Operator Contact}

The Bureau continues to meet regularly with ExxonMobil, the reservoir operator, to discuss results and plan future activities. At then request of the operator, we completed an analysis of eight proposed infill drilling locations on the western flank of the field using a combination of geological models derived from our outcrop and subsurface work and 3D seismic data provided by Oxy Corporation. This analysis was compiled into a Power Point presentation and forwarded to ExxonMobil for use in selecting optimum candidate sites for drilling. Because most of the wells in the targeted area do not have modern porosity logs, the $3 \mathrm{D}$ seismic analysis performed by the Bureau provides a vastly improved picture of the probable porosity distribution in this area.

ExxonMobil subsequently asked the Bureau to analyze the remainder of the field for infill drilling and recompletion opportunities. This second analysis was completed and 
findings and recommendations were delivered to ExxonMobil in September, also in Power Point. These recommendations were based on both 3D seismic and production data and will provide the best guide for selecting drilling locations that have the greatest potential to produce economically significant volumes of oil. ExxonMobil plans to begin drilling wells in early 2004.

\section{Technology Transfer}

We organized and conducted a workshop in May to present preliminary findings of the study. The title of the workshop was "New Methods for Locating and Recovering Remaining Hydrocarbons in the Permian Basin". The workshop, was co-sponsored by the Bureau, the Petroleum Technology Transfer Council, and the University of Texas System Lands Office and was held at the Center for Economic and Energy Diversification in Midland/Odessa. The agenda (Appendix 1) includes other DOE- and University-funded research being conducted by the Bureau along with the results of the Fullerton Clear Fork project. Presentations based the Fullerton project study are listed in bold type. Fullerton project presentations were also presented at the annual meeting of the West Texas Geological Society in Midland/Odessa in October (Appendix 2).

\section{Future Work}

Key elements of remaining work to be done on the project include the following: (1) use of geostatistical approaches to examine optimum ways to distribute reservoir properties in interwell space, (2) use of 3D seismic to constrain distribution of reservoir properties in interwell space, (3) construction of 3D virtual reality model to aid in visualizing model design and 
reservoir flow. Each of these activities has been delayed until basic reservoir characterization activities were completed. All activities are well into the planning stages and implementation will begin soon.

\section{Project Schedule}

We requested and were granted a project no-cost extension from the original completion date of $10 / 31 / 03$. The new project end date is $4 / 30 / 04$. This extension was necessitated by the 6 month delay in beginning the project. We are now making excellent progress on the goals of the project. 
APPENDIX 1. Agenda for "New Methods for Locating and Recovering Remaining Hydrocarbons in the Permian Basin" Workshop; . Center for Economic and Energy Diversification in Midland/Odessa, May 29, 2004. Presentations on Fullerton clear Fork project shown in bold.

\section{ORAL PRESENTATIONS}

Overview of Bureau of Economic Geology research in the Permian Basin:

Eric Potter, Associate Director for Energy, Bureau of Economic Geology

Overview of University Lands West Texas Operations:

F. Stephen Hartmann, Executive Director of University Lands

Overview of PTTC Programs in the Permian Basin:

Bob Kiker, PTTC Texas Region Permian Basin Director

"Oil and gas resource assessment of University Lands, Permian Basin, West Texas": Eugene M. Kim and Stephen C. Ruppel

"Predicting and characterizing fractures in the Ellenburger: using the link between diagenesis and fracturing": Julia F. W. Gale 
"Pore networks in Lower Ordovician Ellenburger Group collapsed paleocave systems: examples from Barnhart field, Reagan County, Texas": Robert A. Loucks and $\underline{\text { Deanna Combs }}$

"Controls on the Distribution and Development of Porosity and Permeability in Clear Fork Reservoirs in the Permian Basin: Stephen C. Ruppel

"Reconditioning seismic data to improve carbonate stratigraphic interpretation and reservoir characterization, Clear Fork Group, Fullerton field, West Texas": $\underline{\text { Zeng }}$

"Better than a porosity cutoff: the rock fabric approach to understanding porosity and permeability in the Lower Clear Fork and Wichita, Fullerton field": $\underline{\text { Rebecca Jones }}$ and F. Jerry Lucia

"Estimation of interparticle/intercrystalline porosity from resistivity logs": Jeff $\underline{\text { Kane }}$

"Defining flow layers in the Lower Clear Fork and Wichita-Albany reservoir of Fullerton field": F. Jerry Lucia

"Regional Yates gas resource assessment and reservoir characterization, Permian Basin, Texas": Eugene M. Kim 


\section{POSTER AND CORE PRESENTATIONS}

“Ellenburger Group Collapsed Paleocave Facies, Barnhart Field, Texas", Deanna Combs, Robert Loucks, and Stephen Ruppel

"Play analysis of major oil reservoirs in the Permian Basin, West Texas": Shirley P. Dutton, Eugene M. Kim, and Mark H. Holtz

"New techniques in fracture imaging and quantification: applications in the Ellenburger Group, West Texas": Leonel Gomez and Julia Gale

"Regional Yates gas resource assessment and reservoir characterization, Permian Basin, Texas", Eugene Kim, Susan Hovorka, and Deanna Combs

"Oil and gas resource assessment of University Lands, Permian Basin, West Texas", Eugene M. Kim and Stephen C. Ruppel

"Vertical distribution of permeability and petrophysical class within the Lower Clear Fork and Wichita: inputs for reservoir modeling at Fullerton field": $\underline{\text { F. Jerry Lucia }}$ and Rebecca Jones

"Clear Fork reservoir architecture and controls on reservoir development: models from outcrop and subsurface data": Stephen Ruppel

"3-D modeling of Clear Fork reservoirs: Fullerton field": Fred Wang 
APPENDIX 2. List of presentations on the Fullerton Clear Fork reservoir project at the West Texas Geological Society Annual Conference in Midland, Texas, on October $7-9,2003$

\section{ORAL TALKS}

Better Than A Porosity Cutoff: The Rock-Fabric Approach To Understanding Porosity And Permeability In The Lower Clear Fork And Wichita Reservoirs, Fullerton Field, West Texas; Rebecca H. Jones, F. Jerry Lucia, Stephen C. Ruppel, and Jeffrey A. Kane

Lower Leonardian (Clear Fork - Abo) Reservoir Architecture: Insights From Outcrops And Fullerton Clear Fork Field, West Texas; Stephen C. Ruppel.

Reconditioning Seismic Data for Improved Reservoir Characterization, Lower Clear Fork and Wichita, Fullerton Field, West Texas; Hongliu Zeng, Stephen C. Ruppel, and Rebecca H. Jones

Estimation Of Interparticle And Separate-Vug Porosities From Resistivity And Total-Porosity Logs; Jeffrey A. Kane

\section{POSTER}

3-D Reservoir Modeling And Simulation Of The Fullerton Clear Fork Unit, Andrews County, West Texas; Fred Wang, F. Jerry Lucia, and Stephen C. Ruppel 